\title{
REFLEXÕES ACERCA DA PARTICIPAÇÃO POPULAR E EFETIVIDADE SOBRE A POLÍTICA NACIONAL DE EDUCAÇÃO AMBIENTAL
}

Vital José Pessoa Madruga Filho ${ }^{1}$

Resumo: $O$ presente trabalho tem por objetivo propiciar uma análise mais aprofundada da normativa legal que rege a Educação Ambiental no Brasil, em especial a Lei no 9.795/99, que instituiu a Política Nacional de Educação Ambiental. A finalidade do estudo foi de estampar a relevância que as normas na tomada de consciência ecológica nos indivíduos. Através de pesquisa bibliográfica e documental, foi possível estabelecer um liame entre a participação social e a eficácia que a norma exerce nas pessoas. Trata-se de pesquisa qualitativa, cuja abordagem fundamentou-se na coleta de dados a partir de leituras e análises.

Palavras-chave: Política Nacional de Educação Ambiental; Legislação; Consciência Ecológica.

\footnotetext{
${ }^{1}$ Mestre e Doutorando em Desenvolvimento pela UFPB. E-mail: vitalpessoa@bol.com.br
} 


\section{Introdução}

Indubitavelmente, a Terra encontra-se atracada numa crise ambiental sem precedentes, oriunda de uma negligência e indiferença das pessoas em relação ao senso de preservação. Diante desse cenário, é certo que a situação reclama por mudanças de hábitos, a fim de assegurar o equilíbrio e a vitalidade do Planeta.

É oportuno salientar que a indigitada crise ambiental, é fruto do processo civilizatório e de globalização experimentados pela modernidade, que almeja um crescimento econômico descomprometido com as reais capacidades suportadas pelo meio ambiente, alimentado pelo consumismo desenfreado que favorece o aumento da pegada ecológica. Lamentavelmente, experimenta-se dessa crise, em razão de uma pseudo noção de desenvolvimento, calculado apenas progresso tecnológico e industrial, aliado a uma concepção de consumo irracional.

Diante desse cenário, a Educação Ambiental exsurge sob o fundamento e instrumento de estratégia capaz de alterar o prumo da história, a partir de uma tomada de consciência e sensibilização das pessoas em prol de uma consciência ecológica.

Assim sendo, com o escopo de melhor contribuir com pensamento atinente ao tema e em vistas a problemática ensaiada, o presente artigo visa viabilizar uma melhor interpretação da normativa que rege a Educação Ambiental no Brasil, através de uma acurada avaliação da eficácia que a norma vem exercendo na vida social, tendo por base a coleta de dados por meio de pesquisa bibliográfica e documental, conferindo à pesquisa caráter qualitativo.

\section{A legislação brasileira sobre Educação Ambiental}

Inicialmente, é preciso compreender a motivação pela qual o Brasil foi motivado a tratar da Educação Ambiental por meio de instrumentos legais e normativos. Desse modo, a Declaração Universal dos Direitos Humanos, estabelecida nos idos de 1948, prescreve que "Toda a pessoa tem direito a um nível de vida suficiente para lhe assegurar e à sua família a saúde e o bemestar".

Nesse compasso, a Conferência de Estocolmo, realizada em 1972, deu origem à Declaração das Nações Unidas sobre o Meio Ambiente, que preconiza em seu princípio primeiro que: qualidade lhe permita viver com dignidade e bem-estar. Ele tem o dever solene de proteger e melhorar o meio ambiente para as gerações presentes e futuras. 
O princípio supra citado foi solenemente recepcionado pela Constituição Federal de 1988, quando prevê capítulo próprio sobre o meio ambiente, fustigado pelo art. 225, salientando no inciso VI do $\S 1^{\circ}$ que é dever do Poder Público favorecer e viabilizar a Educação Ambiental em todos os níveis escolares, além do dever de fomentar políticas públicas voltadas para a conscientização das pessoas em vistas de se assegurar a preservação ambiental.

A importância de se constitucionalizar a Educação Ambiental é suscitada por Kelsen (1987, p. 240), quando afirma que a estrutura do ordenamento jurídico deve ser compreendida, metaforicamente, na figura de uma pirâmide, em que o seu topo é ocupado pela Carta Magna, "que dá validade a todas as outras leis que com ela estiverem em consonância".

A despeito disso, deve-se recordar que a Lei no 6.938/1981, que precedeu o texto constitucional, responsável pela instituição da Política Nacional do Meio Ambiente, já mencionava a importância da Educação Ambiental, quando preconizava em seu art. $2^{\circ}$, inciso $X$, a necessidade de viabilizá-la em todos os níveis de ensino escola, incluindo as práticas educacionais mais remotas, nas zonas rurais e em ambientes comunitários, com o fito de qualificar as pessoas em prol de uma atuação consciente e ativa na luta pela preservação ambiental.

Outrossim, a Lei no 5.197/1967, que dispõe sobre a proteção à fauna, já prelecionava em seu art. 35, que a adoção de livros escolares de leitura estavam condicionados à textos alusivos a proteção da fauna, prevendo ainda, que os programas de ensino deveriam contemplar duas aulas anuais sobre a temática atinente à Educação Ambiental.

Com efeito, tem-se que a positivação da Educação Ambiental, e sua posterior constitucionalização, evidenciou a importância do tema, atraindo a necessidade de regulamentação normativa, na esperança de conferir maior eficácia ao mister estabelecido na Carta Magna. Nesse cenário, exsurge a Lei no 9.795/99, que possui normatização por parte do Decreto no 4.281/02, que dispõe propriamente sobre a Educação Ambiental e institui a Política Nacional de Educação Ambiental (PNEA). A lei retro citada pontifica que a EA é um item necessário e fundamental para a educação nacional, e deve ser concatenada em todos os níveis do ambiente escolar e da formação básica e superior do Brasil, em caráter formal e informal.

Trata-se de um instrumento estratégico que facilita e viabiliza a tomada de consciência das pessoas acerca da importância da preservação ambiental, uma vez que o ambiente escolar e acadêmico é muito importante para a construção de valores sociais e culturais, além de ser um difusor nato de conhecimentos e habilidades, voltados em proveito de alguns princípios básicos, que servem de alicerce à implementação e estruturação básica da EA, os quais estão previstos no art. 4º, in verbis: 
Art. 4 São princípios básicos da Educação Ambiental:

I - o enfoque humanista, holístico, democrático e participativo;

II - a concepção do meio ambiente em sua totalidade, considerando a interdependência entre o meio natural, o socioeconômico e 0 cultural, sob 0 enfoque da sustentabilidade;

III - o pluralismo de ideias e concepções pedagógicas, na perspectiva da inter, multi e transdisciplinaridade;

IV - a vinculação entre a ética, a educação, o trabalho e as práticas sociais;

$\mathrm{V}$ - a garantia de continuidade e permanência do processo educativo;

$\mathrm{VI}$ - a permanente avaliação crítica do processo educativo;

VII - a abordagem articulada das questões ambientais locais, regionais, nacionais e globais;

VIII - o reconhecimento e o respeito à pluralidade e à diversidade individual e cultural.

Em suma, os princípios básicos ora estabelecidos, possui a finalidade de alçar conquistas relativas aos objetivos da EA, que segundo Adams (2012, p. 2153), de forma sintética, tais fundamentos primam pela generalidade, interdependência, pluralismo, ética, articulação, crítica, direito, respeito, cidadania planetária, enfim, conceitos que visam o fortalecimento e a internalização da EA como componente propulsor da formação cidadã.

Nesse sentido, em harmonia com os princípios supra citados, a Lei fixa os objetivos fundamentais inerentes à Educação Ambiental, vejamos:

Art. 5o São objetivos fundamentais da Educação Ambiental:

I - o desenvolvimento de uma compreensão integrada do meio ambiente em suas múltiplas e complexas relações, envolvendo aspectos ecológicos, psicológicos, legais, políticos, sociais, econômicos, científicos, culturais e éticos;

II - a garantia de democratização das informações ambientais;

III - o estímulo e o fortalecimento de uma consciência crítica sobre a problemática ambiental e social;

IV - o incentivo à participação individual e coletiva, permanente e responsável, na preservação do equilíbrio do meio ambiente, entendendo-se a defesa da qualidade ambiental como um valor inseparável do exercício da cidadania;

V - o estímulo à cooperação entre as diversas regiões do País, em níveis micro e macrorregionais, com vistas à construção de 
uma sociedade ambientalmente equilibrada, fundada nos princípios da liberdade, igualdade, solidariedade, democracia, justiça social, responsabilidade e sustentabilidade;

VI - o fomento e o fortalecimento da integração com a ciência e a tecnologia;

VII - o fortalecimento da cidadania, autodeterminação dos povos e solidariedade como fundamentos para o futuro da humanidade.

Com efeito, depreende-se que os objetivos ora alçados, tendem ao favorecimento de uma educação preocupada com a formação de um senso crítico em atenção ao meio ambiente, conjugando fatores socioambientais e de cidadania, contemplando o caráter democrático e universal que devem ser apresentados em prol de práticas alusivas à Educação Ambiental (ADAMS, 2012, p. 2154).

Destarte, depreende-se que o legislador emitiu claramente o seu desejo de imprimir caráter participativo às ações de Educação Ambiental, cujo denoto é de natureza cristalina, quando da análise dos princípios e objetivos que regem a $E A$, cujas diretrizes exigem o envolvimento da sociedade como um todo, em particular a escola, que se apresenta como território fértil capaz de favorecer a solidificação de uma consciência ecológica e cidadã, haja vista que se trata de ambiente propício à formação humana.

Nesse norte, conforme lição apresentada por Minc (2005, p. 71),

As escolas devem funcionar como polos irradiadores de consciência ecológica, envolvendo as famílias e a comunidade. Escolas podem defender lagos, reflorestar encostas, abrigar centros de reciclagem.

Cumpre suscitar que a formação cidadã, deve orientar o indivíduo a uma atuação política, na medida em que resta possibilitada a contribuição para uma construção de uma coletividade atenta aos valores socioambientais (SORRENTINO et al. 2005, p. 287).

Desse modo, resta evidente que o PNEA possui por finalidade o despertar de uma consciência ecológica lúcida e orientada, cuja diretriz deve ser estabelecida por meio de programas ambientais tecnicamente estruturados e capazes de atingir à população como um todo (SANTOS, 2000).

Assim, seguindo a estratégia abordada por David S. Wood e Diane Walton Wood no trabalho "Como Planificar un Programa de Educacion Ambiental", tem-se que para atingir o êxito em seu ponto mais evidente, é preciso um criterioso processo de planejamento e uma séria política voltada para sua execução, a fim de cumprir determinadas etapas, quais sejam: a) 
análise do contexto ambiental; b) individuação do público; c) adoção da mensagem; d) escolha de uma proposta educativa; e e) avaliação.

Com base nesses elementos basilares, destaque-se que 0 art. 10, da Lei no 9.795/99, dispõe que a EA deverá ser fomentada a partir de prática educativa integrada, contínua e permanente, inibindo a criação de disciplina específica no currículo de ensino, salvo se for o caso de cursos de pósgraduação e extensão, desde que sejam correlatos à EA. Dessa forma, os conceitos atrelados ao conteúdo material de Educação Ambiental, deverão ser absorvidos pelas disciplinas curriculares da educação básica. Para tanto, conforme dicção do art. 11 do mesmo diploma legal, os aspectos inerentes ao meio ambiente e à consciência ecológica, devem estar presentes na formação curricular dos professores, em todas as disciplinas e níveis.

Nesse toar, considerando o aspecto transversal inato à EA, Tavares (2013, p. 83) ensina que:

A Educação Ambiental surge com a responsabilidade de provocar uma transformação da linearidade, disciplinaridade, dicotomia inerente das nossas práticas educativas e tem como desafio o rompimento com essa lógica. As discussões em âmbito nacional e internacional direcionam para que apenas por uma prática interdisciplinar, em que o meio ambiente seja entendido como um todo sem fronteiras, perpassando transversalmente todas as áreas do conhecimento, é que o objetivo da Educação Ambiental poderá ser vislumbrado.

Complementando o pensamento supra, Mazzarino, Munhoz, Keil (2013, p. 59) reforça o sentido de transversalidade próprio da EA, na medida em que "é possível que sintamos a Educação Ambiental na pele, e não pelo intelecto apenas, libertando-nos num currículo rizomático, que proporcione novas ancoragens semióticas e transversas".

Dessa forma, resta pacífica a ideia de que a importância que este diploma legal exerce, aliado às práticas participativas nele previstas, é capaz de promover o tão almejado desenvolvimento sustentável, calcado numa ativa participação política, devidamente dotada de conscientização ambiental.

Paralelo a tudo isso, e exercendo importância de igual teor, a Lei oㅡ 9.985/2000, que instituiu o Sistema Nacional de Unidade de Conservação da Natureza - SNUC demonstra preocupação ambiental pertinente à finalidade para a qual foi criado.

Tem-se que o termo educação apresenta-se de forma constante e contumaz na sobredita legislação, uma vez que a conservação da natureza só pode ser alcançada mediante um processo paulatino capaz de esclarecer e orientar as pessoas à vida política. Na verdade, esse convite à participação é tão latente, que até mesmo onde as visitações públicas são terminantemente 
proibidas, como é o caso das estações ecológicas e reservas biológicas, a lei excetua a visitação quando a mesma for motivada por circunstâncias educacionais.

De forma dialogal e articulada, outros diplomas legais supervenientes tratam precipuamente da Educação Ambiental, como é o caso da Lei no 11.284/2006, que dispõe sobre a gestão de florestas públicas para a produção sustentável, estabelecendo em seu art. $41, \S 1^{\circ}$, que os recursos advindos do Fundo Nacional de Desenvolvimento Florestal - FNDF deverão ser investidos em projetos que favoreçam a "[...] VII-Educação Ambiental". Outro exemplo, diz respeito à criação do Instituto Chico Mendes de Biodiversidade, surgido por força da Lei no. 11.516/2007, de modo que a Educação Ambiental deve ser inspirada, fomentada e executada no âmbito da autarquia federal, conforme prevê $\mathrm{o}$ art. $1^{\circ}$, III, da lei retro.

Nessa esteira, tanto a Lei ํo. 12.305/2010 (que institui a Política Nacional de Resíduos Sólidos), quanto a Lei ㄲo. 11.445/2007 (que institui a Política Nacional de Saneamento Básico) reservam tratamento especial à EA, como ferramenta imprescindível capaz de promover uma gestão integrada, e viabilizar a redução, a reutilização e a reciclagem dos resíduos sólidos.

Nesse interim, para coroar a importância que a EA deve exercer perante a sociedade, a Lei no 12.633/2012, instituiu o Dia Nacional da Educação Ambiental, como forma de despertar a sociedade para a importância do tema, cujo festejo ocorre no dia 3 de junho, por toda a extensão territorial brasileira.

Em face do exposto, depreende-se que o ordenamento jurídico pátrio é dotado de diversos diplomas que privilegiam a EA como prática necessária à viabilização do direito fundamental ao meio ambiente ecologicamente equilibrado. De modo que, a eficácia e a positividade dos resultados dependerão de um nível consciente de participação cidadão na vida política do Brasil.

\section{Exercício participativo nas normas brasileiras e efetividade da Educação Ambiental}

Conforme as observações até então observadas, depreende-se que a EA no Brasil vem se consolidando através do tempo, sob um viés predominantemente participativo, na medida em que a intervenção coletiva nesse processo vem tomando prestígio e acentuada influência nos documentos legais que guardam pertinência temática com a EA.

Nesse sentir, Fiorillo (2008, p. 53) afirma que "a Educação Ambiental é decorrente do princípio da participação, onde se busca trazer uma consciência ecológica à população, titular do direito ao meio ambiente".

No mesmo raciocínio, Morimoto (2014, p. 287), acrescenta que: 
Diversos foram os autores que defenderam uma relação estreita entre o aumento do acesso ao conhecimento e a motivação, tanto para a mudança de atitudes individuais e coletivas, quanto para 0 envolvimento com causas socioambientais, incluindo ai, o incremento no engajamento e na participação em processos decisórios. Isto porque, o conhecimento pode abrir caminhos para a avaliação crítica da realidade e tal avaliação pode também evoluir para a busca por soluções para os problemas da coletividade.

Nesse sentido, tem-se que as pessoas devem se sentir motivada à participação da vida política e social, a fim de exercer um direito elementar constituído pela cidadania, capaz de conferir a cada indivíduo o poder de tomar decisões em prol do interesse coletivo (DALLARI, 2004).

A participação popular faz remissão a um conceito genérico e abstrato atrelado à ideia relativa à defesa dos interesses do povo, oportunizando a inclusão dos mais diversos setores da sociedade em proveito da proteção ambiental, na medida em que todos os indivíduos, independente de qualificação, cor, raça, credo, nível de instrução e etc. estão inseridos num mesmo contexto social, suscetível aos efeitos e consequências oriundos de decisões oponíveis à sociedade (MORIMOTO, 2014).

Por isso que Pereira, Ferreira (2008) aponta que a efetiva participação popular, é capaz de enaltecer os mais nobres valores arraigados ao conceito de cidadania, de modo que o interesse pelo enlace ambiental se justifica, na medida em que o equilíbrio ecológico é objeto de realização integral do ser humano, apresentando deferência direta com os níveis de qualidade de vida, o que instaura o conceito de ecocidadão, cuja importância deve ser demasiadamente festejada em sociedade.

Como já afirmado, o art. 225 do texto constitucional, confere ao meio ambiente o status de direito fundamental, cuja tutela reserva-se ao Poder Público, bem como à sociedade como um todo, com o fito de garantir sua preservação para as presentes e futuras gerações.

Além desse dever constitucional em favor da defesa do meio ambiente atribuído a toda sociedade, não se pode esquecer que de igual modo, a Lei nº. 11.284/2006, que lida com a gestão de florestas públicas para a produção sustentável, admite o caráter participativo, quando prevê no bojo do art. $41, \S 2^{\circ}$ que o Fundo Nacional de Desenvolvimento Florestal, deverá subjugar-se sob à égide de um conselho consultivo, composto por entes federativos e representantes da sociedade civil organizada (BRASIL, 2006).

Da mesma forma, a Lei $\mathrm{n}$ ‥9.985/2000 (BRASIL, 2000), que criou o Sistema Nacional de Unidades de Conservação - SNUC admite de igual modo, a intervenção popular, in verbis: 
Art. 5․ O SNUC será regido por diretrizes que:

II - assegurem os mecanismos e procedimentos necessários ao envolvimento da sociedade no estabelecimento e na revisão da política nacional de unidades de conservação;

III - assegurem a participação efetiva das populações locais na criação, implantação e gestão das unidades de conservação. (grifo nosso)

No âmbito da PNEA, ressalte-se o caráter participativo carreado pelo diploma legal, cujo princípio básico da EA deve deter-se ao enfoque humanista, holístico, democrático e participativo. Nessa mesma alusão, é objetivo fundamental o incentivo à participação individual e coletiva, que conjugando todos esses elementos, demonstram a importação que a intervenção popular exerce sobre os mecanismos de EA (BRASIL, 1999).

Todavia, a eficácia da lei fica condicionada à ações concretas e voltadas para o respeito ao meio ambiente, sem o qual, toda essa gama legiferante poderá tornar-se inócua e sem sentido no contexto nacional.

Portanto, não se pode olvidar em políticas públicas direcionadas ao empoderamento popular, por intermédio da ampliação dos níveis de conhecimento da população em geral e a abertura de canais afeitos ao desenvolvimento de políticas cidadãs e canais tendentes à tomada de decisões e de controle social.

Atente-se, por último, ao que giza Portella (2000, p. 97) que salienta grande ameaça à efetividade da lei, quando da ausência de elementos de identificação e de cultura jurídica associada à imponência do poder econômico, que se sobrepõe e rege procedimentos em detrimento do bem da coletividade.

\section{Considerações Finais}

Pelo estudo inferido, atrelado aos interesses da lei e da participação social, tem-se que o disciplinamento é extremamente vasto e capaz de contemplar as finalidades e motivações encampadas pela Legislação nacional.

No entanto, a simples positivação de normas e enunciados em leis e a consequente necessidade de se obter mecanismos de controle e preservação do meio ambiente, não são suficientes para tal desiderato.

Por assim dizer, no atual contexto brasileiro, entorno da diversidade de leis, tem-se que a norma ou é cumprida ou é questionada, de modo que a eficácia da lei não requer empatia da população para com o seu conteúdo, mas o esforço que a mesma deve exercer para se amoldar ao cumprimento da norma, como forma de se reservar dignidade e respeito ao homem, bem como ao meio ambiente em que o indivíduo está situado e inserido, de sorte que o progresso das participações cidadãs apenas amplia, enriquece e concretiza a Educação Ambiental.

revista brasileira educação ambiental 


\section{Referências}

ADAMS, B.G. A importância da Lei 9795/99 e das Diretrizes Curriculares Nacionais da Educação Ambiental para Docentes. Monografias Ambientais REMOA/UFSM. Cascavel, no 10: p. 2148-2157, out-dez/2012. Disponível em: <http://cascavel.ufsm.br/revistas/ojs-2.2.2/index.php/remoa/article/view/6926>. Acesso em 25/05/2018.

BOFF, L. Saber cuidar: ética do humano - compaixão pela terra. $11^{\mathrm{a}} \mathrm{ed}$. Petrópolis: Vozes, 1999.

BRASIL. Constituição da República Federativa do Brasil, de 05 de outubro de 1988. Disponível em:

$<$ <ttp://www.planalto.gov.br/ccivil_03/constituicao/constituicao.htm>. Acesso em

25/04/2018.

BRASIL. Lei no. 5.197 de 03 de janeiro de 1967 . Disponível em:<http://www.planalto.gov.br/ccivil_03/leis/L5197.htm>. Acesso em: 04/05/2018.

BRASIL. Lei no. 6.938 de 31 de agosto de 1981 . Disponível em:<http://www.planalto.gov.br/ccivil_03/leis/L6938.htm>. Acesso em: 04/05/2018.

BRASIL. Lei no. 9.795 de 27 de abril de 1999 . Disponível em:<http://www.planalto.gov.br/ccivil_03/leis/L9795.htm>. Acesso em: 04/05/2018.

BRASIL. Lei no. 9.985 de 18 de julho de 2000. Disponível em: <http://www.planalto.gov.br/ccivil_03/leis/L9985.htm>. Acesso em: 04/05/2015.

BRASIL. Lei no. 11.284 de 02 de março de 2006. Disponível em: <http://www.planalto.gov.br/ccivil_03/leis/L11284.htm>. Acesso em: 04/05/2015.

BRASIL. Lei no. 11.516 de 28 de agosto de 2007. Disponível em: <http://www.planalto.gov.br/ccivil_03/_ato2007-

2010/2007/lei//11516.htm>.Acesso em: 02/06/2018.

BRASIL. Lei no. 11.445 de 05 de janeiro 2007. Disponível em: <http://www.planalto.gov.br/ccivil_03/_ato2007-2010/2007/lei//11445.htm>. Acesso em: 02/06/2018.

BRASIL. Lei no. 12.305 de 02 de agosto de 2010. Disponível em: <http://www.planalto.gov.br/ccivil_03/_ato2007-2010/2010/lei//12305.htm>. Acesso em: 03/06/2018.

BRASIL. Lei no. 12.633 de 14 de maio de 2012. Disponível em: <http://www.planalto.gov.br/ccivil_03/_Ato2011-

2014/2012/Lei/L12633.htm>.Acesso em 05/06/2018.

CHIAVENATO, J.J. 0 Massacre da natureza. $2^{\underline{a}}$ ed. São Paulo: Moderna, 2005. 
DALLARI, D.A. O Que é Participação Política? São Paulo: Brasiliense, 2004.

DECLARAÇÃO DAS NAÇÕES UNIDAS SOBRE O MEIO AMBIENTE HUMANO. Disponível na Biblioteca Virtual de Direitos Humanos da Universidade de São Paulo: < $\underline{w w w . d i r e i t o s h u m a n o s . u s p . b r}>$. Acesso em 25/04/2018.

DECLARAÇÃO UNIVERSAL DOS DIREITOS HUMANOS. Disponível na Biblioteca Virtual de Direitos Humanos da Universidade de São Paulo: $<$ <ww.direitoshumanos.usp.br>. Acesso em 25/04/2018.

FIORILLO, C.A.P. Curso de Direito Ambiental Brasileiro. 9a ed. São Paulo: Saraiva, 2008.

KELSEN, H. Teoria Pura do Direito. São Paulo: Martins Fontes, 1987. MACHADO, J.T. Educação Ambiental: um estudo sobre a ambientalização do cotidiano escolar. 2014. 245f. Tese (Doutorado em ciências). Programa de Pós-Graduação da Escola Superior de Agricultura "Luiz de Queiroz" - USP. Piracicaba, 2014.

MAZZARINO, J.M.; MUNHOZ, A.V.; KEIL, J.L. Currículo, Transversalidade e Sentidos em Educação Ambiental. Revbea. Rio Grande, V. 7, No 2: 51-61, 2012.

MINC, C. Ecologia e cidadania. 2ª ed. São Paulo: Moderna, 2005. MORIMOTO, I.A. Direito e Educação Ambiental: estímulo à participação crítica e à efetiva aplicação de normas voltadas à proteção ambiental no Brasil. 2014 . 501f. Tese (Doutorado em ciência ambiental). Programa de Pós-Graduação em Ciência Ambiental (PROCAM) da Universidade de São Paulo. São Paulo, 2014.

PEREIRA, D.; FERREIRA, R. Ecocidadão. Secretaria do Meio Ambiente do Estado de São Paulo. São Paulo: SMA/CEA, 2008.

PORTELLA, C.A. A ineficácia das normas constitucionais ambientais. Revista Direito em Debate. 2000. v. 9, n. 14 . p. 97-117.

SANTOS, A.S.R. Educação Ambiental e o Poder Público. Disponível em: $<$ http://www.aultimaarcadenoe.com.br/educacao-ambiental/>. Acesso em 26/05/15.

SEN, A.K. Desenvolvimento como liberdade. São Paulo: Companhia das Letras, 2000.

SORRENTINO, M.; TRAJBER, R.; MENDONÇA, P.; FERRARO JÚNIOR, L.A. Educação Ambiental como política pública. Educação e Pesquisa. São Paulo, V. 31, n. 2, p. 285-299, maio-ago/2005.

TAVARES, G.S. O que pensam os professores sobre a criação de uma disciplina de Educação Ambiental? Revbea. Rio Grande, V. 8, No 1, p.83-90, 2013. 